\title{
Older but not wiser
}

Almost all peer reviewers get worse, not better, over time, suggests a study presented on 10 September at the Sixth International Congress on Peer Review and Biomedical Publication in Vancouver, Canada.

Michael Callaham, editor-in-chief of the Annals of Emergency Medicine in San Francisco, California, analysed the scores that editors at the journal had given more than 1,400 reviewers between 1994 and 2008. The journal routinely has its editors rate reviews on a scale of one to five, with one being unsatisfactory and five being exceptional. Ratings are based on whether the review contains constructive, professional comments on study design, writing and interpretation of results, providing useful context for the editor in deciding whether to accept the paper.

The average score stayed at roughly 3.6 throughout the entire period. The most surprising result, however, was how individual reviewers' scores changed over time: $93 \%$ of them went down, which was balanced by fresh young reviewers coming on board and keeping the average score up. The average decline was 0.04 points per year.

"I was hoping some would get better, and I could home in on them. But there weren't enough to study," says Callaham. Less than 1\% improved at any significant rate, and even then it would take 25 years for the improvement to become valuable to the journal, he says.

Others are not so convinced that older reviewers aren't wiser. "This is a quantitative review, which is fine, but maybe a qualitative study would show something different," says Paul Hébert, editor of the Canadian Medical Association Journal in Ottawa. A thorough review might score highly on the Annals scale, whereas a less thorough but more insightful review might not, he says. "When you're young you spend more time on it and write better

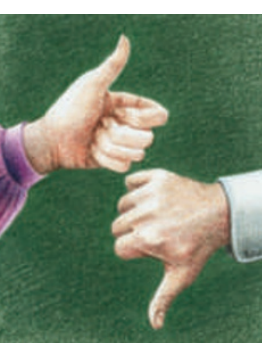
reports. But I don't want a young person on a panel when making a multi-million-dollar decision."

Callaham agrees that a select few senior advisers are always very useful. But from his own observation, older reviewers do tend to cut corners. He notes that psychological research shows that experts in complex tasks typically reach a plateau and then stay there or slowly deteriorate. Perhaps by the time researchers are asked to review a paper at his journal, they are already experts. He suspects the same would hold true for journals across all fields.

Callaham also found that a mentoring programme at the Annals, in which new reviewers are paired up with senior ones, has only a temporary effect. Young reviewers assigned a mentor typically scored half a point better than non-mentored colleagues, but when the mentor's watchful eye disappeared after a year or so, this advantage evaporated. And the Annals dropped a separate peerreview training course some time ago, he notes, because although people loved it, it wasn't helping their scores. "It's kind of depressing," he says.

\section{Nicola Jones}

\section{POSTDOC JOURNAL}

\section{A natural haven}

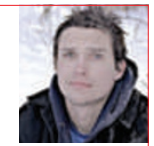

Having worked as both a theorist and an experimentalist, I find theoretical work to be the most challenging emotionally because it's the most isolating. In my last postdoc, as an experimentalist, I relied on and interacted with other people for such daily tasks as preparing reagents. Work-based socializing was common. Now, as a theorist, I write computer code and solve equations by myself. Sometimes I go for days without any meaningful human interaction.

Isolation is not new to me.
I grew up in a rural area, and when I felt sad or lonely I would head into the woods to look for birds, snakes and salamanders. Knowing the creatures around me made the world seem a little bit friendlier and less alien. But now, surrounded by the concrete of Baltimore, I no longer have an easy escape into the woods. So when a friend invited me to explore the Potomac River, about an hour away from Baltimore, I eagerly agreed.

Floating downriver on rubber inner-tyre tubes, we watched an osprey plunge into the water, saw a young bald eagle perched on a bank, heard the distinctive call of a barred owl and glimpsed a nighthawk hunting over the river at dusk. Thanks to this river retreat, my life of equations and computer code back in the city seems better, even days later. To paraphrase the author and naturalist Henry David Thoreau: not yet subdued by man, nature's presence refreshes him.

Sam Walcott is a postdoc in theoretical biophysics at Johns Hopkins University in Baltimore, Maryland.
IN BRIEF

\section{CBI rallies industry}

UK companies should play a bigger role in higher education, says a new report from the Confederation of British Industry (CBI). In Stronger Together: Business and Universities in Turbulent Times, the CBI, a lobbying organization, suggests that science, technology, engineering and mathematics (STEM) education would improve if industry provided, for example, increased input on course content and more work-experience opportunities. Students need more information about the "value business places on particular skills", says the report (see http://highereducation. cbi.org.uk). A 2009 CBI survey found that two-thirds of science, high-tech and information-technology UK firms believed the content of STEM degrees was not relevant to their needs.

\section{Indians fast in protest}

More than 1,500 science and engineering faculty members at the Indian Institutes of Technology (IITs) held a one-day hunger strike on 24 September.

The All-India IIT Faculty Federation is seeking withdrawal of two government rules: one barring IITs from recruiting professors with fewer than four years of teaching experience and assistant professors with fewer than three, and one capping the proportion of professors who can be promoted to a senior grade at $40 \%$.

Federation president Muthuveerappan Thenmozhi says the rules undermine the autonomy of IITs and hamper recruitment. The federation also wants entry-level faculty salaries higher than the proposed 30,000 renminbi (US\$625) per month.

\section{Europe's research lagging}

The quality, rate and results of scientific research in Europe lag behind those in the United States, according to a 21 September report from the Organisation for Economic Co-operation and Development (OECD). The Economic Survey of the European Union 2009 report says government regulations stymie scientific collaboration and innovation because of a general lack of mobility of researchers across Europe. Many are forced to stay in a particular institution or country, it says, to retain research grants, for example. Nigel Pain, OECD senior economist and a report author, says easing mobility would facilitate research and innovation, and potentially create more research posts. 